\title{
Comparative analysis of drought-responsive and -adaptive genes in Chinese wingnut (Pterocarya stenoptera C. DC)
}

\author{
Yong $\mathrm{Li}^{i^{*}}$, Yu-Tao Si${ }^{1}$, Yan-Xia $\mathrm{He}^{2}$ and Jia-Xin $\mathrm{Li}^{1}$
}

\begin{abstract}
Background: Drought is the main stress factor for the cultivation of Pterocarya stenoptera in urban areas, and this factor will cause its dehydration and affect its growth. Identifying drought-related genes will be useful for understanding the drought adaptation mechanism of $P$. stenoptera.

Results: We used physiological indicator detection, comparative transcriptome sequencing, and reanalysis on the results of previous landscape genomics studies to investigate the drought adaptation mechanism in P. stenoptera. The changes in malondialdehyde content showed that $P$. stenoptera was remarkably affected by drought stress, and the increase in soluble sugar content suggested its important role in response to drought stress. Results of comparative transcriptome sequencing showed that $P$. stenoptera initiated a series of programs, such as increasing the gene expression of unsaturated fatty acids, tyrosine, and plant pathogen resistance, to deal with the transient drought stress. According to the annotated results in a previous study, P. stenoptera adapts to the long-term differential drought stress by regulating the thickness of cell walls and expressing upper or lower limits of the downstream genes in the hormone signaling pathway. Through the comparative analysis of drought-responsive and -adaptive genes in $P$. stenoptera, this study supports the hypothesis that the environment-responsive genes (ERGs) introduced by the transient environmental stresses will be substantially more than the environment-adaptive genes (EAGs) in response to long-term differential environmental stresses, and the EAGs are not necessarily ERGs.

Conclusions: Our study identified drought-responsive and -adaptive genes in $P$. stenoptera and revealed that $P$. stenoptera increased the gene expression of unsaturated fatty acids, tyrosine, and plant pathogen resistance in response to transient drought stress. This study reveals the different adaptation mechanism of $P$. stenoptera under the transient and long-term differential drought stresses.
\end{abstract}

Keywords: Drought-adaptive gene, Drought-responsive gene, Drought stress, Pterocarya stenoptera, Transcriptome

\section{Background}

The rapid global climate change is aggravating the environmental stresses faced by plants under the field, such as high temperature, cold, drought, and soil salinization [1, 2]. Among these environmental stresses, drought stress is an important factor that limits plant growth and

\footnotetext{
*Correspondence: liyongrui1@126.com

'Innovation Platform of Molecular Biology, College of Landcape and Art, Henan Agricultural University, Zhengzhou, China

Full list of author information is available at the end of the article
}

development $[3,4]$. Plants will undergo morphogenesis or physiological changes in response to drought stress $[5,6]$. These morphogenesis or physiological changes are usually due to the changes in sequence and expression of drought-related genes. Identifying the drought-related genes will be useful for understanding the drought adaptation mechanism of P. stenoptera [7].

At present, two strategies are generally adopted to identify genes related to environmental stress at the genome level. The first strategy is the comparative transcriptome

(c) The Author(s). 2021 Open Access This article is licensed under a Creative Commons Attribution 4.0 International License, which permits use, sharing, adaptation, distribution and reproduction in any medium or format, as long as you give appropriate credit to the original author(s) and the source, provide a link to the Creative Commons licence, and indicate if changes were made. The images or other third party material in this article are included in the article's Creative Commons licence, unless indicated otherwise in a credit line to the material. If material is not included in the article's Creative Commons licence and your intended use is not permitted by statutory regulation or exceeds the permitted use, you will need to obtain permission directly from the copyright holder. To view a copy of this licence, visit http://creativecommons.org/licenses/by/4.0/. The Creative Commons Public Domain Dedication waiver (http://creativecommons.org/publicdomain/zero/1.0/) applies to the data made available in this article, unless otherwise stated in a credit line to the data. 


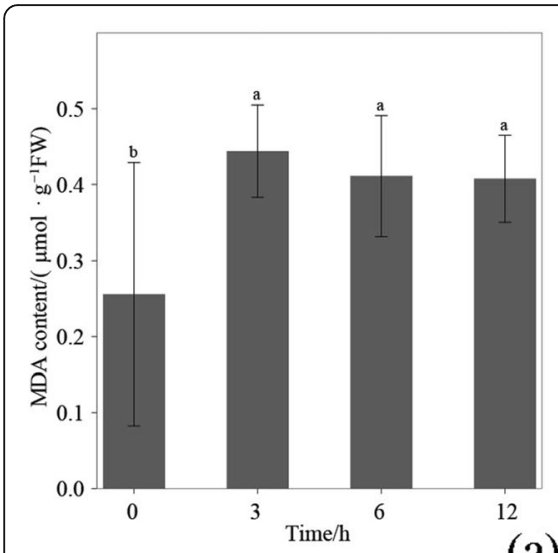

(a)
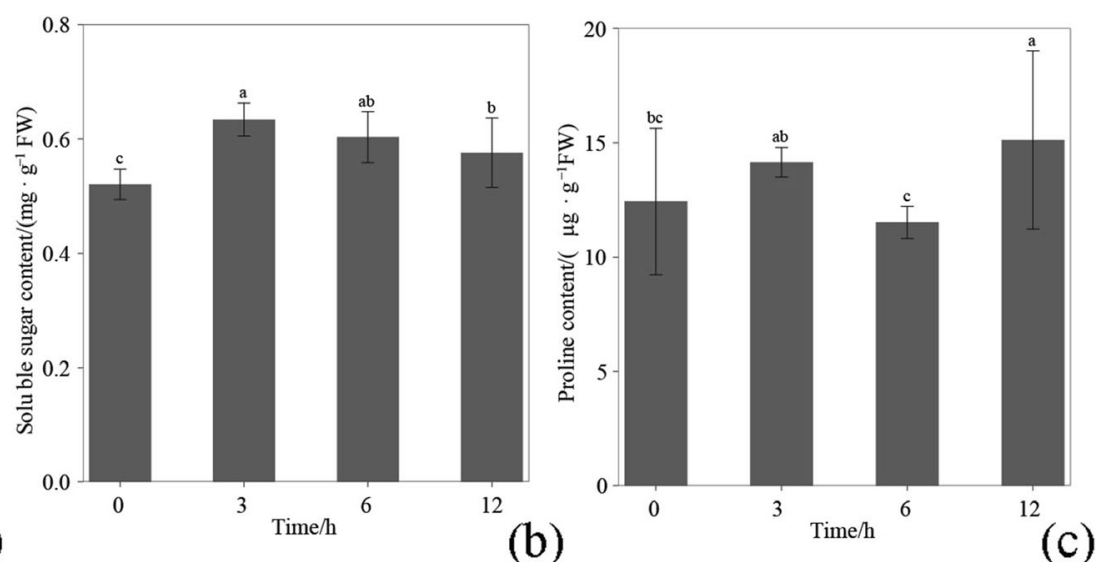

Fig. 1 The content of a MDA, b SS, c Pro in leaves of Pterocarya stenoptera after $0 \mathrm{~h}, 3 \mathrm{~h}, 6 \mathrm{~h}$, and $12 \mathrm{~h}$ exposure to drought stress conditions. The data represents mean values $\pm \mathrm{SD}(n=3)$. Different letters indicate significant difference at $P<0.05$

analysis by using the samples before and after environmental stresses. The related genes are up- or downregulated under the stimulation of environmental stresses [8]. The species quickly respond to environmental stresses through the transient up- or down-regulation in gene expression. The genes identified by this strategy are defined as environment-responsive genes (ERGs) in this study. Increasing studies using this strategy improve the understanding of the adaptation mechanism of plants [9]. The second strategy is environment correlation analysis in landscape genomics. Individuals with different genotypes in the natural population have different survival or reproduction rates due to the spatial environmental heterogeneity $[10,11]$. These environmental stresses leave selection signals on the genome of species after a long period of natural selection [12]. The genes related to

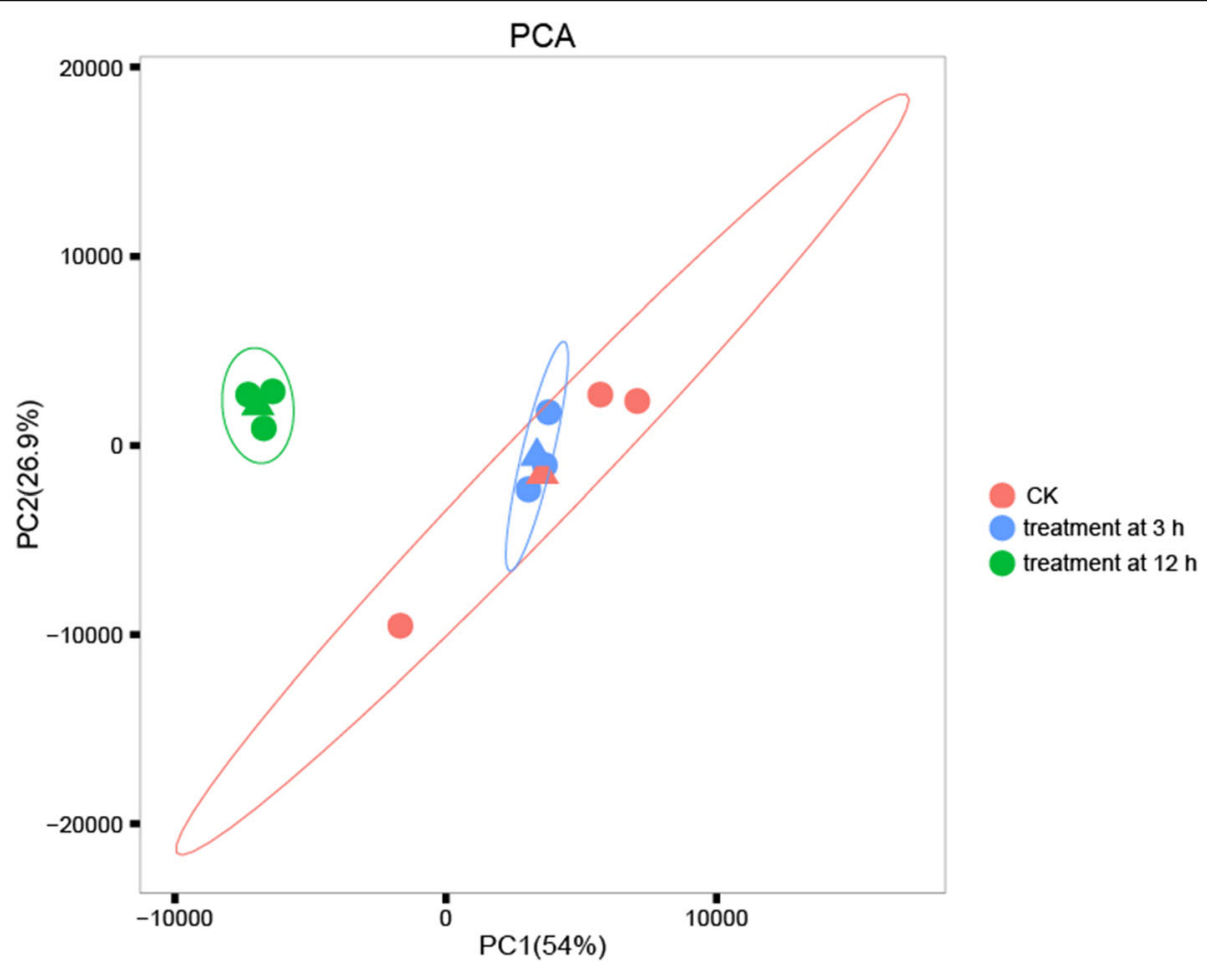

Fig. 2 Principal component analysis of gene expression based on FPKM. Principal component 1 (PC1; 54\% of variance) plotted against principal component 2 (PC2; $26.9 \%$ of variance). Red symbols correspond to control samples, blue symbols to treatment samples at $3 \mathrm{~h}$, green symbols to treatment samples at $12 \mathrm{~h}$ 

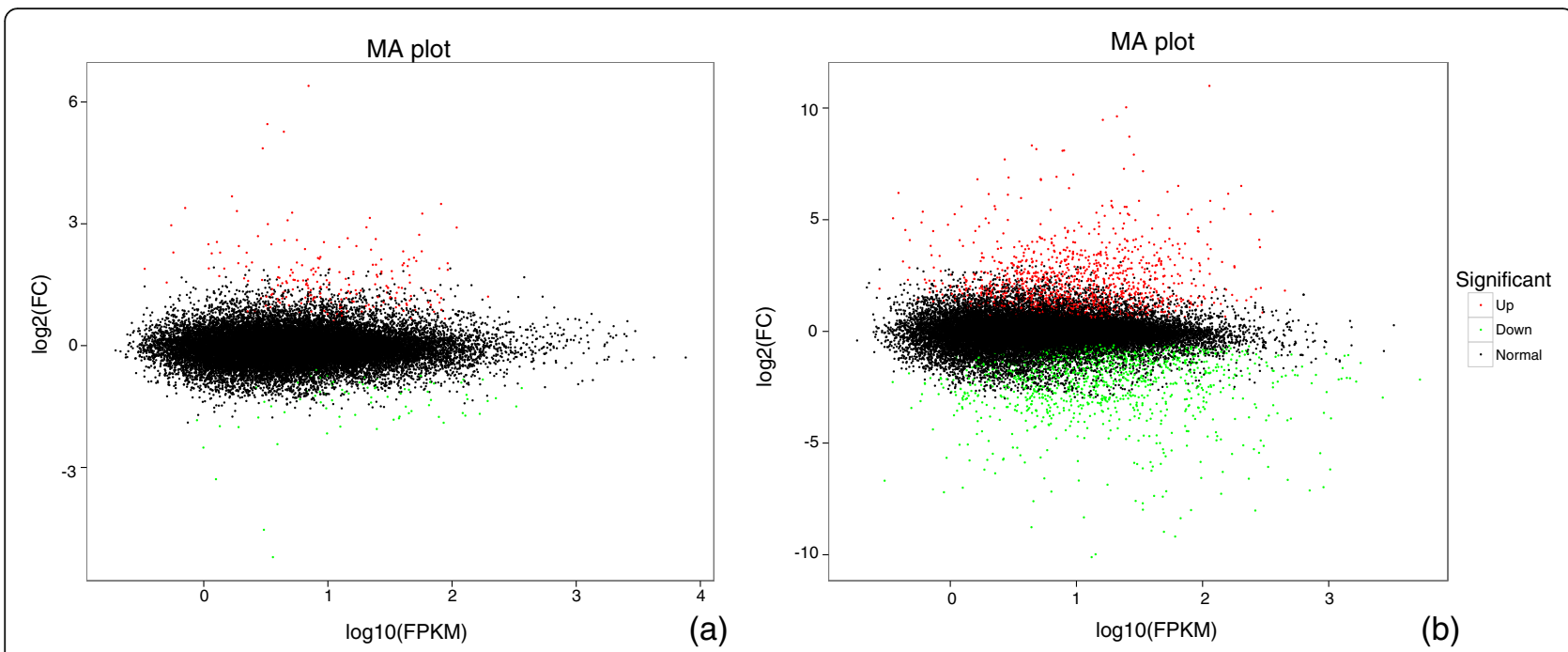

Fig. 3 The MA plot to display the different expressed genes in leaves of Pterocarya stenoptera after $3 \mathrm{~h}(\mathbf{a})$ and $12 \mathrm{~h}$ (b) exposure to drought stress conditions when FC $\geq 1.5$. The abscissa indicates the value of the Log2(FC) difference between the two groups; the ordinate indicates the value of the log10(FPKM) of the two groups. The green dots represents down-regulated genes, the red dots represents up-regulated genes, and the black dots represents non-differentially expressed genes

environmental stresses are identified through gene detection with selection signals and correlation analysis between the genes and the corresponding environmental factors [13]. This strategy has been confirmed to be a highly effective approach in many previous studies [1416]. The identified genes using the second strategy show sequence adaptive differentiation under the long-term natural selection, while those identified by the first strategy demonstrate changes in their expression under the shortterm environmental stresses. The genes identified by the second strategy are defined as environment-adaptive genes (EAGs). However, limited studies have focused on the relationships between the ERGs and EAGs identified by the two strategies. Therefore, a new hypothesis is proposed as follows: the ERGs introduced by the transient environmental stresses will be considerably higher than the EAGs caused by the long-term differential environmental stresses, and the EAGs are not necessarily ERGs.

Chinese wingnut (Pterocarya stenoptera C. DC, Juglandaceae) is a dominant tree species in deciduous broadleaved forests in China's warm temperate and subtropical regions. This species grows along streams and in wetlands in the field. It is frequently used in urban landscaping in recent years because of its excellent ornamental properties [17]. When P. stenoptera is used as an urban landscaping tree, the water supply is obviously less than when grown in the field, this condition results in drought stress. Recent studies in P. stenoptera suggested that drought stress has remarkable effects on multiple physiological indicators, and long-term drought stress causes seedling death $[18,19]$. To date, no published studies have reported the molecular adaptation mechanism in P. stenoptera under drought stress. The landscape genomics study on $P$. stenoptera, which provides insight into EAGs, has been recently conducted [20].

Transcriptomic analysis and physiological index detection were performed in this study to investigate the gene expression and physiological process changes in P. stenoptera under simulated drought stress. Comparative analysis between the drought-responsive genes (DRGs) and drought-adaptive genes (DAGs) identified in previous studies was conducted to reveal the relationships between them. The main objectives of the present study are as follows: (i) screen for drought-tolerant ERGs and characterize the adaptation mechanism in response to transient drought stresses, and (ii) reveal the relationships of ERGs introduced by the transient environmental stresses and the EAGs caused by the long-term differential environmental stresses.

\section{Results}

\section{Physiological changes under simulated drought stress treatment}

The malondialdehyde (MDA) content in leaf under the simulated drought stress was obviously higher than that under the control, while that after cold stress did not continuously increase (Fig. 1a). The results showed that the membrane system was damaged by simulated drought stress. Moreover, soluble sugar (SS) substantially increased after simulated drought stress and then gradually decreased from $6 \mathrm{~h}$ to $12 \mathrm{~h}$, but the SS contents at 6 and $12 \mathrm{~h}$ were still higher than those in the control (Fig. 1b). However, the proline (Pro) content did not 
Table 1 The GO and KEGG enrichment for up- and down- regulated DEGs at the early stage ( $3 \mathrm{~h}$ ) with FC $\geq 1.5$

\begin{tabular}{|c|c|c|c|}
\hline ID & Description & $p$-value & $q$-value \\
\hline \multicolumn{4}{|l|}{ Up-regulated } \\
\hline \multicolumn{4}{|c|}{ KEGG Enrichment } \\
\hline ko03008 & Ribosome biogenesis in eukaryotes & $1.46 \mathrm{E}-11$ & $1.36 \mathrm{E}-0 \mathrm{~s}$ \\
\hline ko04626 & Plant-pathogen interaction & 1.07E-08 & $9.91 \mathrm{E}-07$ \\
\hline ko00071 & Fatty acid degradation & $8.46 \mathrm{E}-07$ & 7.87E-05 \\
\hline ko00592 & alpha-Linolenic acid metabolism & $9.29 \mathrm{E}-07$ & 8.64E-05 \\
\hline ko04712 & Circadian rhythm - plant & $1.53 \mathrm{E}-05$ & $1.42 \mathrm{E}-03$ \\
\hline \multicolumn{4}{|l|}{ GO Enrichment } \\
\hline GO:0032549 & ribonucleoside binding & $1.23 \mathrm{E}-06$ & $5.48 \mathrm{E}-04$ \\
\hline GO:0003899 & DNA-directed 5'-3' RNA polymerase activity & $3.15 \mathrm{E}-06$ & $1.40 \mathrm{E}-03$ \\
\hline GO:0009982 & pseudouridine synthase activity & $1.44 \mathrm{E}-05$ & $6.41 \mathrm{E}-03$ \\
\hline GO:0004004 & ATP-dependent RNA helicase activity & $1.79 \mathrm{E}-05$ & $7.98 \mathrm{E}-03$ \\
\hline GO:0005739 & mitochondrion & $3.59 \mathrm{E}-06$ & $5.27 \mathrm{E}-04$ \\
\hline GO:0009570 & chloroplast stroma & $1.43 \mathrm{E}-05$ & $2.10 \mathrm{E}-03$ \\
\hline GO:0032040 & small-subunit processome & $1.44 \mathrm{E}-05$ & $2.12 \mathrm{E}-03$ \\
\hline GO:0006351 & transcription, DNA-templated & $6.58 \mathrm{E}-09$ & $3.83 \mathrm{E}-06$ \\
\hline GO:0000373 & Group II intron splicing & $2.49 \mathrm{E}-07$ & 1.45E-04 \\
\hline GO:0050789 & regulation of biological process & $7.51 \mathrm{E}-07$ & 4.37E-04 \\
\hline GO:0010478 & chlororespiration & $5.22 \mathrm{E}-06$ & $3.04 \mathrm{E}-03$ \\
\hline GO:0010501 & RNA secondary structure unwinding & $8.14 \mathrm{E}-06$ & $4.74 \mathrm{E}-03$ \\
\hline \multicolumn{4}{|l|}{ Down-regulated } \\
\hline \multicolumn{4}{|c|}{ KEGG Enrichment } \\
\hline ko04141 & Protein processing in endoplasmic reticulum & $2.44 \mathrm{E}-05$ & $1.54 \mathrm{E}-03$ \\
\hline \multicolumn{4}{|l|}{ GO Enrichment } \\
\hline GO:0004512 & inositol-3-phosphate synthase activity & $1.22 \mathrm{E}-08$ & $1.95 \mathrm{E}-06$ \\
\hline GO:0000155 & phosphorelay sensor kinase activity & $9.80 \mathrm{E}-06$ & $1.57 \mathrm{E}-03$ \\
\hline GO:0006021 & inositol biosynthetic process & $1.47 \mathrm{E}-08$ & 3.37E-06 \\
\hline GO:0019419 & sulfate reduction & 7.26E-08 & 1.67E-05 \\
\hline GO:0009638 & phototropism & $2.92 \mathrm{E}-06$ & $6.72 \mathrm{E}-04$ \\
\hline
\end{tabular}

demonstrate remarkable changes after simulated drought stress (Fig. 1c).

\section{Molecular responses under simulated drought stress}

Clean reads of the nine cDNA libraries of $P$. stenoptera treated by control and drought at early ( $3 \mathrm{~h}$ ) and late $(12 \mathrm{~h})$ stages ranged from $40,451,520$ to $45,950,810$, GC percentages ranged from 45.39 to $46.75 \%$, and mapped reads ranged from $37,684,795$ to $42,896,134$ (Additional file 1: Table S1). The Q30 values of nine sequencing samples varied from 92.8 to $93.6 \%$, which indicated that the output data were qualified for further analysis. The sequencing data were stored in the National Center for Biotechnology Information database (SRX71878217187829; BioProject PRJNA589251).

RNA-seq provided information on the DRGs in P. stenoptera under drought stress at early and late stages.
Principal component analysis (PCA) was used to identify expression differences of all genes among all samples (Fig. 2). The PCA loading plot indicated that the effect of drought stress on the overall gene expression of the samples was small at $3 \mathrm{~h}$, but it was significant at $12 \mathrm{~h}$.

Compared with the control, 290 genes including 210 up-regulated and 80 down-regulated genes were significantly differently expressed at the early stage of drought stress when the parameter was set to fold-change (FC) $\geq$ 1.5 (Fig. 3a). Based on these DRGs, 5 pathways and 12 ontologies were up-regulated, 1 pathway and 5 ontologies were down-regulated (Table 1). With the extension of stress time, DRGs significantly increased, and 2374 genes including 1166 up-regulated and 1208 downregulated genes were differentially expressed at the late stage (Fig. 3b). Based on these DRGs, 4 pathways and 3 ontologies were up-regulated, 5 pathways and 30 
Table 2 The GO and KEGG enrichment for up- and down- regulated DEGs at the late stage (12 h) with FC $\geq 1.5$

\begin{tabular}{|c|c|c|c|}
\hline ID & Description & $p$-value & $q$-value \\
\hline \multicolumn{4}{|l|}{ Up-regulated } \\
\hline \multicolumn{4}{|c|}{ KEGG Enrichment } \\
\hline ko04712 & Circadian rhythm - plant & $8.46 \mathrm{E}-14$ & $5.92 \mathrm{E}-12$ \\
\hline ko00350 & Tyrosine metabolism & 4.24E-06 & 2.97E-04 \\
\hline ko00592 & alpha-Linolenic acid metabolism & $9.60 \mathrm{E}-06$ & $6.72 \mathrm{E}-04$ \\
\hline ko00591 & Linoleic acid metabolism & $1.18 \mathrm{E}-04$ & $8.26 \mathrm{E}-03$ \\
\hline \multicolumn{4}{|l|}{ GO Enrichment } \\
\hline GO:0016168 & chlorophyll binding & $6.69 \mathrm{E}-04$ & $3.02 \mathrm{E}-06$ \\
\hline GO:0004022 & alcohol dehydrogenase (NAD) activity & 7.83E-04 & 3.54E-06 \\
\hline GO:0019887 & protein kinase regulator activity & 4.75E-03 & 2.15E-05 \\
\hline \multicolumn{4}{|l|}{ Down-regulated } \\
\hline \multicolumn{4}{|c|}{ KEGG Enrichment } \\
\hline ko00196 & Photosynthesis - antenna proteins & 4.94E-32 & $5.23 \mathrm{E}-30$ \\
\hline ko00195 & Photosynthesis & $1.25 \mathrm{E}-13$ & $1.33 \mathrm{E}-11$ \\
\hline ko00710 & Carbon fixation in photosynthetic organisms & $6.04 \mathrm{E}-07$ & $6.40 \mathrm{E}-05$ \\
\hline ko01200 & Carbon metabolism & 1.36E-05 & 1.44E-03 \\
\hline ko00860 & Porphyrin and chlorophyll metabolism & 7.30E-05 & 7.74E-03 \\
\hline \multicolumn{4}{|l|}{ GO Enrichment } \\
\hline GO:0016168 & chlorophyll binding & $2.72 \mathrm{E}-31$ & 1.35E-28 \\
\hline GO:0031409 & pigment binding & 3.98E-18 & 1.97E-15 \\
\hline GO:0010277 & chlorophyllide a oxygenase [overall] activity & 4.74E-11 & 2.35E-08 \\
\hline GO:0030267 & glyoxylate reductase (NADP) activity & $2.50 \mathrm{E}-07$ & $1.24 \mathrm{E}-04$ \\
\hline GO:0016618 & hydroxypyruvate reductase activity & $2.50 \mathrm{E}-07$ & 1.24E-04 \\
\hline GO:0016620 & $\begin{array}{l}\text { oxidoreductase activity, acting on the aldehyde or oxo } \\
\text { group of donors, NAD or NADP as acceptor }\end{array}$ & 4.69E-07 & $2.32 \mathrm{E}-04$ \\
\hline GO:0009881 & photoreceptor activity & 5.83E-07 & 2.89E-04 \\
\hline GO:0051537 & 2 iron, 2 sulfur cluster binding & 2.64E-06 & $1.31 \mathrm{E}-03$ \\
\hline GO:0000155 & phosphorelay sensor kinase activity & $1.08 \mathrm{E}-05$ & $5.35 \mathrm{E}-03$ \\
\hline GO:0004512 & inositol-3-phosphate synthase activity & $1.13 \mathrm{E}-05$ & $5.58 \mathrm{E}-03$ \\
\hline GO:0015112 & nitrate transmembrane transporter activity & 1.35E-05 & $6.68 \mathrm{E}-03$ \\
\hline GO:0008878 & glucose-1-phosphate adenylyltransferase activity & 1.35E-05 & $6.68 \mathrm{E}-03$ \\
\hline GO:0009522 & photosystem I & $7.29 \mathrm{E}-32$ & 9.69E-30 \\
\hline GO:0010287 & plastoglobule & 4.63E-27 & $6.15 \mathrm{E}-25$ \\
\hline GO:0009535 & chloroplast thylakoid membrane & $2.10 \mathrm{E}-13$ & 2.79E-11 \\
\hline GO:0009507 & chloroplast & $5.18 \mathrm{E}-08$ & $6.90 \mathrm{E}-06$ \\
\hline GO:0009654 & photosystem II oxygen evolving complex & $5.61 \mathrm{E}-08$ & 7.46E-06 \\
\hline GO:0009538 & photosystem I reaction center & 7.27E-06 & 9.67E-04 \\
\hline GO:0018298 & protein-chromophore linkage & $6.27 \mathrm{E}-33$ & 3.85E-30 \\
\hline GO:0009768 & photosynthesis, light harvesting in photosystem I & $9.65 \mathrm{E}-23$ & $5.93 \mathrm{E}-20$ \\
\hline GO:0009416 & response to light stimulus & $9.88 \mathrm{E}-14$ & 6.07E-11 \\
\hline GO:0009765 & photosynthesis, light harvesting & $2.15 \mathrm{E}-11$ & $1.32 \mathrm{E}-08$ \\
\hline GO:0015979 & photosynthesis & 1.62E-09 & 9.94E-07 \\
\hline GO:0042549 & photosystem II stabilization & 3.37E-08 & 2.07E-05 \\
\hline GO:0019252 & starch biosynthetic process & $2.55 \mathrm{E}-06$ & $1.56 \mathrm{E}-03$ \\
\hline
\end{tabular}


Table 2 The GO and KEGG enrichment for up- and down- regulated DEGs at the late stage (12 h) with FC $\geq 1.5$ (Continued)

\begin{tabular}{clll}
\hline ID & Description & $\boldsymbol{p}$-value & \\
\hline GO:0032957 & inositol trisphosphate metabolic process & $5.79 \mathrm{E}-06$ & $3.56 \mathrm{E}-03$ \\
GO:0009585 & red, far-red light phototransduction & $7.88 \mathrm{E}-06$ & $4.84 \mathrm{E}-03$ \\
GO:0006021 & inositol biosynthetic process & $1.05 \mathrm{E}-05$ & $6.42 \mathrm{E}-03$ \\
GO:0010143 & cutin biosynthetic process & $1.21 \mathrm{E}-05$ & $7.45 \mathrm{E}-03$ \\
GO:0000160 & phosphorelay signal transduction system & $1.49 \mathrm{E}-05$ & $9.17 \mathrm{E}-03$ \\
\hline
\end{tabular}

ontologies were down-regulated (Table 2). Compared with the control, 233 genes including 174 up-regulated and 59 down-regulated genes were significantly differently expressed at the early stage of drought stress when the parameter was set to FC $\geq 2$ (Fig. 4a). Based on these DRGs, 1 pathway and 2 ontologies were up-regulated and 2 pathways and 8 ontologies were down-regulated (Additional file 1: Table S2). With the extension of stress time, DRGs significantly increased, and 2090 genes including 1044 up-regulated and 1046 down-regulated genes were differentially expressed at the late stage (Fig. $4 \mathrm{~b})$. Based on these DRGs, 6 pathways and 9 ontologies were up-regulated and 4 pathways and 25 ontologies were down-reguated (Additional file 1: Table S3).

Consistent with the FC threshold values with $\geq 1.5$ and 2 , the pathway of circadian rhythm - plant was significantly up-regulated at $3 \mathrm{~h}$, and the ontology of chlororespiration was significantly down-regulated (Table 1 and Additional file 1: Table S2). When the FC threshold dropped to $\geq 1.5$, the genes in metabolism of alphalinolenic acid metabolism and plant-pathogen interaction were also significantly up-regulated. At the time of drought stress for $12 \mathrm{~h}$, alpha-linolenic acid metabolism, linoleic acid metabolism, plant-pathogen interaction, circadian rhythm-plant, and tyrosine metabolism were significantly up-regulated; at this time, the genes of multiple pathways and ontologies related to photosynthesis were significantly down-regulated (Table 2 and Additional file 1: Table S3). In addition, the genes in nitrate transport and starch synthesis were significantly down-regulated.

\section{Candidate DAGs in response to long term drought natural selection}

We reanalyzed previously published data on adaptive evolution to identify DAGs in response to long-term drought natural selection. According to the LFMM results in previous landscape genomics studies, 188 SNPs were strongly associated with principal component 1 (PC1) axis. PC1 represented precipitation in the driest seasons in previous studies. Among these SNPs, 24 and 95 SNPs were respectively annotated by the KEGG and GO databases (Additional file 1: Table S3). The SNPs annotated by KEGG database were further analyzed in detail. A total of 14 genes were regarded as candidate DAGs based on the annotated results of 24 SNPs. Among these candidate DAGs, only 3 genes including 2

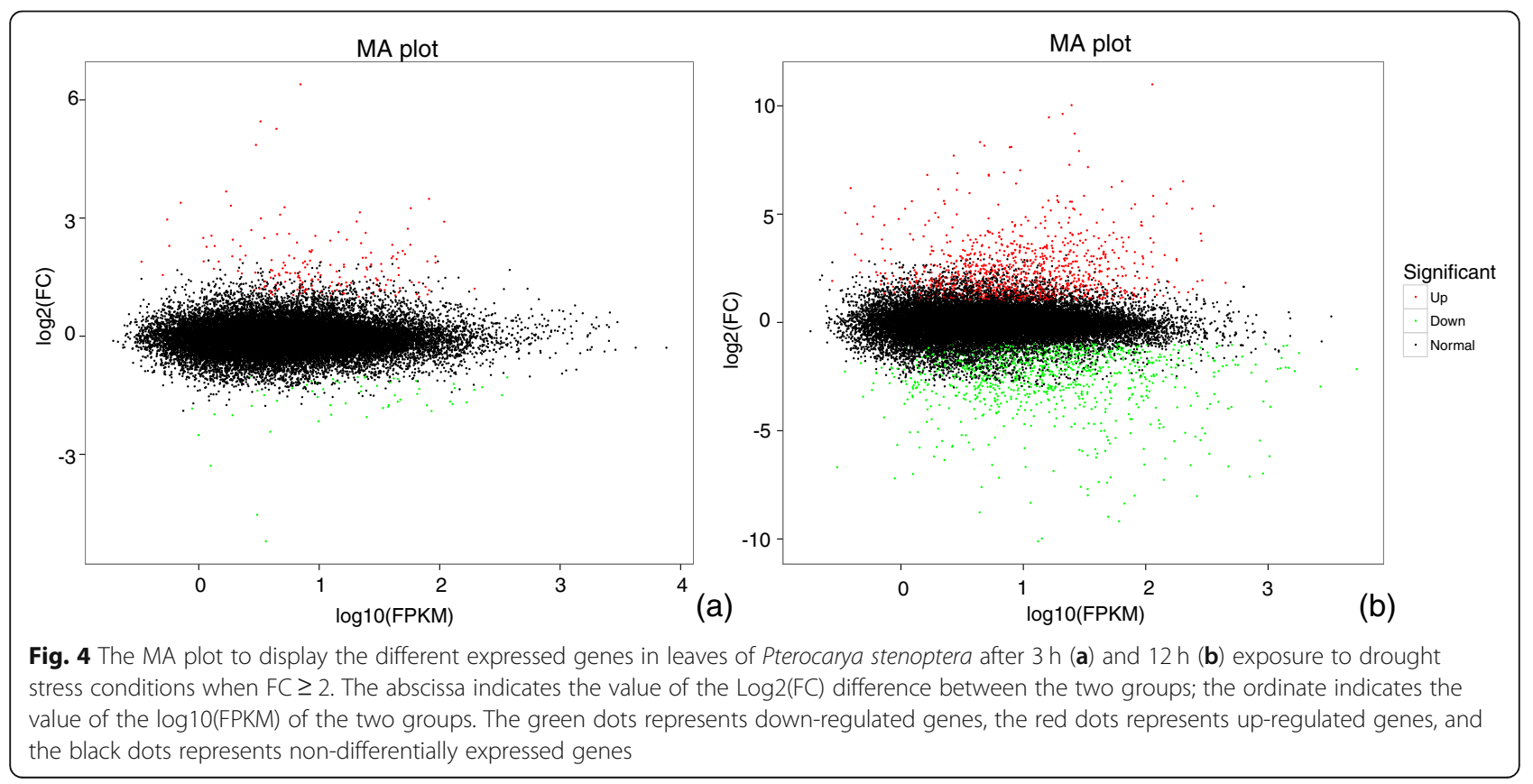


up- and 1 down-regulated genes,were DRGs under the simulated drought stress treatment.

\section{Quantitative real-time PCR validation}

Eight DRGs consisting of 5 up- and 3 down-regulated genes under drought stress were used to verify the RNA-Seq results through quantitative real-time PCR ( $q$ RT-PCR). The eight genes were mostly related to posttranslational modification, lipid and amino acid transport and metabolism, and energy production and conversion (Additional file 1: Table S4). The RNA-seq data was confirmed to be reliable based on the DRGs of $q$ RT-PCR results. Pearson correlation coefficient $(r=$ $0.756, P<0.001)$ showed that significant positive correlation existed between $q$ RT-PCR and RNA data.

\section{Discussion}

Plants respond to drought stress through a series of morphogenesis, physiological, and molecular processes [21-23]. The effective high-throughput sequencing technique considerably facilitates the investigation of the adaptation mechanisms of drought stress [24]. Revealing the signaling pathways responsible for drought stress will provide clues for the cultivation and maintenance of urban landscaping plants.

$P$. stenoptera is widely used in landscape greening due to its excellent ornamental properties [17]. It is usually used in cities for street trees and solitary tree planting in parks. However, the water supply of $P$. stenoptera in urban cultivation is substantially lower than that in the field. The hardening of urban road surface reduced the infiltration of rain water and intensified the drought stress on P. stenoptera. Thus, P. stenoptera shows obvious dehydration symptoms in its leaves. For better cultivation and maintenance of $P$. stenoptera, it is necessary to detect the adaptive response of $P$. stenoptera under drought stress. Here, the physiological indicators and gene expression of $P$. stenoptera were determined. The increase in MDA content indicated that drought stress damaged the membrane system of $P$. stenoptera. In response to the change in cellular osmotic pressure introduced by the damage of the membrane system, the SS content significantly increased at the early stage of drought stress. The same response pattern has been found in other previous reports $[1,25]$. However, the Pro content did not demonstrate significant changes compared with those in control. This finding indicated that Pro did not participate in the regulation of osmotic pressure under drought stress.

The results of RNA-seq showed that 290 and 2374 DRGs with $\mathrm{FC} \geq 1.5$ at the early and late stages were introduce by drought stress. The up- or down- regulated pathways and ontologies of DRGs showed a considerable amount of information on P. stenoptera response or adaptability under drought stress. At the early stage, the circadian rhythm-plant, alpha-linolenic acid metabolism, and plant-pathogen interaction were significantly upregulated. The genes in circadian rhythm plays an important role in the response and adaptation of plants to environmental stress. Recent study showed drought impacts the oscillation of circadian clock genes in soybean [26]. Our results showed that drought significantly affected the endogenous rhythm system of P. stenoptera, which might induce a complex network regulation system, including the expression of DRGs. In plants, fatty acid metabolic pathways play a key role in plant defense. Low level of gene expression in alpha-linolenic acid can increase the damage degree on plants under drought stress. Increasing the synthesis of linolenic acid can reduce the effects of drought stress on plants [27]. Our results also showed that the drought tolerance of $P$. stenoptera was improved by increasing the gene expression of alpha-linolenic acid. The differential expression genes caused by drought stress and plant antigens have a crosstalk. Drought stress induces an overall response of key plant hormones that not only respond to water stress, but also play a key role in plant responses to pathogens [28]. The genes related to plant-pathogen interaction pathway are usually up-regulated under drought stress [29]. Over all, the genes of pathways of circadian rhythm - plant, alpha-linolenic acid metabolism and plant-pathogen interaction were up-regulated to respond to drought stress in the early stage of P. stenoptera. At the late stage, most down-regulated pathways and ontologies are associated with chloroplast and photosynthesis, which showed that photosynthesis is significantly affected by drought stress. This significant effect of drought stress on photosynthesis has also been reported in other studies [30,31]. In addition, the downregulated DRGs related to nitrate transport and starch synthesis showed that drought stress might limit the nutrient absorption and carbohydrate synthesis of plants [32]. Drought stress affected the growth of $P$. stenoptera and decreased the expression of genes in photosynthetic and nutrient absorption. In the late stage, several metabolic pathways, namely, circadian rhythm-plant, alphalinolenic acid metabolism, and plant-pathogen interaction,that were upregulated in the early stage were found. In addition, the up-regulated genes were increased in linoleic acid metabolism and tyrosine metabolism. Linoleic acid metabolism and alpha-linolenic acid metabolism share a common pathway, and multiple genes overlap between them. The DRGs related to alpha-linolenic acid metabolism and linoleic acid metabolism suggested that $P$. stenoptera increased drought tolerance by maintaining membrane fluidity and integrity by modulating linolenic acid levels during drought stress [33]. The DRGs related to tyrosine enhance stress 
resilience by influencing osmotic changes and ROS detoxification [34].

Overall, the DRGs provided a considerable amount of information on the response of P. stenoptera to the transient drought stress. Under the transient drought stress, $P$. stenoptera initiated a series of programs, including increasing the gene expression of unsaturated fatty acids, tyrosine, and plant pathogen resistance, to cope with drought stress. Meanwhile, drought stress limited the nutrient absorption and carbohydrate synthesis in $P$. stenoptera.

Compared with a large amount of DRGs introduced by transient drought stress, a small amount of DAGs was produced in the natural population under the longterm differential drought stress. A total of 14 candidate DAGs were obtained on the basis of the annotated results from the SNPs identified by LFMM analysis using KEGG database [20]. The most identified DAGs did not overlap with DRGs, and only three DAGs were DRGs. Among these DAGs, caffeic acid 3-O-methyltransferase and cellulose synthase A enhanced drought tolerance by participating in cell wall synthesis $[35,36]$. Ethyleneresponsive transcription factor and molybdenum cofactor sulfurase increase drought tolerance by participating in the hormone signaling pathway $[37,38]$. Overall, the number of DAGs is much smaller than that of DRGs. Although the two research strategies are used to search for drought related genes, they obviously find two types of genes in different meanings. In the dry season, natural populations suffer drought stress, while the degree of drought stress is different due to the spatial environmental heterogeneity. The population needs only a small number of gene sequence differentiation to treat this different intensity selection pressure. DRGs in these populations still play the most important role in the face of drought stress [39]. However, the DAGs of sequence differentiation can respond to different intensity drought stresses because of their different gene efficacies. The results of DAGs suggested that P. stenoptera adapted to the differential drought stress by regulating the thickness of cell walls and the upper or lower limits of the downstream genes in the hormone signaling pathway, while the results of DRGs suggested that $P$. stenoptera adapted to transient drought stress by increasing the gene expression of unsaturated fatty acids, tyrosine, and plant pathogen resistance. The abovementioned results indicate that DAGs identified by landscape genomics and DRGs identified by comparative transcriptomics have obviously different meanings. However, they are all related to drought, while DRGs will be significantly more than DAGs. Our results also confirm that most of the two types of genes have only a small intersection. Although EAGs were considerably less than ERGs, these individuals with highly efficient EAGs were substantially useful in screening germplasm resources from natural populations for breeding. Overall, the present results support the hypothesis that the ERGs introduced by the transient environmental stresses will be considerably higher than the EAGs in response to long-term differential environmental stresses, and the EAGs are not necessarily ERGs.

\section{Conclusions}

Physiological indicator detection, transcriptome sequencing, and reanalysis of the results of previous landscape genomics study were used to reveal the drought adaptation mechanism in P. stenoptera. The obtained results indicated that $P$. stenoptera increased the gene expression of unsaturated fatty acids, tyrosine and plant pathogen resistance, to respond to transient drought stress. $P$. stenoptera adapted to the long-term differential drought stress by regulating the thickness of cell walls and the upper or lower limits of the downstream genes in the hormone signaling pathway. The obtained results supported the hypothesis that the ERGs introduced by the transient environmental stresses will be considerably higher than the EAGs in response to long-term differential environmental stresses, and the EAGs were not necessarily ERGs. This study reveals the different adaptation mechanism of $P$. stenoptera under the transient and long-term differential drought stresses.

\section{Methods}

\section{Culture and growth of plant materials}

The P. stenoptera seeds were obtained from Shuyang Jiuluolika Seed Co., Ltd. in Jiangshu. Stratification treatment were firstly performed on these seeds under $4{ }^{\circ} \mathrm{C}$ for 30 days, the seeds were then sterilized in $0.5 \%$ $\mathrm{K}_{2} \mathrm{M}_{\mathrm{n}} \mathrm{O}_{4}$ solution. Afterward, the seeds were transferred into culture dishes with two layers of wet filter paper until the radicle burst the testa. The seedlings were further replanted to a nutrient bowl $(9 \mathrm{~cm} \times 11 \mathrm{~cm})$ with one strain per pot. The seedlings were cultured in the artificial climate chest (PLD-500-G4, Ledian Instrument Manufacturing Co., Ltd). The culture conditions were set as follows: $20,000 \mathrm{~lx}$ illumination intensity, $27 / 22^{\circ} \mathrm{C}$ $(14 / 10 \mathrm{~h}$ at day/night), and $60 \%$ air relative humidity. After the seedlings were cultured for 6 months, the whole seedlings were transplanted into a $100 \mathrm{~mL}$ conical flask containing 1/2 Hoagland's nutrient solution for seedling recovery. The treatment of seedling recovery was conducted in the artificial climate chest for 1 month. The seedlings with the same and vigorous growth were selected as the experimental materials. These seedlings were then treated by using the $1 / 2$ Hoagland's nutrient solution containing $10 \%\left(\mathrm{~g} \mathrm{~mL}^{-1}\right)$ polyethylene glycol (PEG-6000). The seedlings were treated at $0,3,6$, and $12 \mathrm{~h}$. The leaves of treated plants 
were randomly selected and immediately transferred into liquid nitrogen and finally stored in a refrigerator at $80^{\circ} \mathrm{C}$. The experimental treatments were designed with three replicates to ensure data reproducibility. The voucher specimen of $P$. stenoptera were identified by Dr. Yong $\mathrm{Li}$ and deposited at the herbarium of College of Landscape and Art, Henan Agricultural University (voucher no. LiPS2019A01).

\section{Detection of physiological indicators}

Three physiological indicators, that is, the contents of MDA, SS, and Pro, were determined to reflect the effects of drought on the P. stenoptera seedlings. MDA is the product of membrane lipid peroxidation, which reflects the damage degree of membrane system under drought stress [40]. The MDA content was determined using thiobarbituric acid method [41]. SS and Pro are both important osmoregulation substances, which can reduce the cell osmotic potential and enhance the water absorption capacity to improve the tolerance or adaptability of plants to drought stress [42]. The SS and Pro contents were determined according to the method of Rosa et al. [43] and Bates et al. [44], respectively. The three physiological indexes were detected using microplate reader Infinite $M$ PLEX (Tecan, Grödig, Austria). These indexes were measured on $0,3,6$, and $12 \mathrm{~h}$ after drought treatment. Three biological replications were set for each treatment. Significance of the results of the physiological indexes were determined using the least-significant difference test $(P<$ 0.05 ) in one-way analysis of variance (ANOVA).

\section{Library construction and transcriptome sequencing}

RNA analyses were performed at 3 and $12 \mathrm{~h}$ after drought treatment, the samples before drought treatment were set as control. All treatments had three bioligical replications. Total RNA was isolated using a plant total RNA Extraction Kit DP432 (Tiangen Technologies, Beijing, China). RNA quality was evaluated using Agilent 2100 (Agilent Technologies, CA, USA) and NanoDrop 2000 (Thermo Fisher Scientific, DE, USA). The sequencing libraries were constructed by using NEBNext Ultra ${ }^{\text {mix }}$ RNA Library Prep Kit according to the manufacturer's protocols. The library quality was further evaluated using Agilent 2100 (Agilent Technologies, CA, USA). Finally, the qualified libraries were sequenced on the HiSeq X Ten system (BioMarker Technologies, Beijing, China).

\section{Mapping sequence reads to the reference genome}

After removing the adapter sequences and low-quality reads from raw reads, the remaining clean reads were subsequently mapped on the draft genome of P. stenoptera [45] by using the software HISAT2 [46] and further assembled by using the software StringTie [47].

\section{Identification and functional annotation of differentially expressed genes (DEGs)}

The gene expression levels in the samples were measured by fragments per kilobase of exon per million fragments mapped using the software StringTie [47]. The average value of FPKM of three samples for each treatment was taken when DEGs was identified. PCA was further performed based on FPKM value of all expressed genes using the plotPCA function in DESeq2 [48] to reveal the broad patterns of variation of nine samples in response to drought stress. The DEGs in P. stenoptera introduced by drought stress were obtained using DESeq2 software [48]. The selection criteria for DEGs was set as false discovery rate $<0.01$ and $\mathrm{FC} \geq 1.5$ and 2 . The function of the DEGs was annotated using the KEGG [49] and GO [50] databases. The identified DEGs were redefined as DRGs due to their rapid response to drought stress. To identify the enriched GO ontologies and KEGG pathways of these DEGs, the statistical enrichment analyses were implemented using the topGO packages [51] in $\mathrm{R}$ and KOBAS [52]. The significant of enrichment pathways and ontologies were determined using $q$-values $<0.01$ as criteria.

\section{Reanalysis of the results of landscape genomics}

To search candidate DAGs, we reanalyzed previously published data [20]. According to previous landscape genomics study, precipitations of the driest month (Bio14) and quarter (Bio17) were strongly associated with $\mathrm{PC} 1$ axis [20]. Therefore, the genes related to $\mathrm{PC} 1$ axis can be regarded as the candidate DAGs. The identified DAGs from the LFMM analysis [53] were reannotated and classified in this study using the KEGG and GO databases.

\section{qRT-PCR validation}

Eight DRGs with the corresponding primers (Addtional file 1: Table S4) were selected to validated their expression levels using $q \mathrm{RT}-\mathrm{PCR}$. The $q \mathrm{RT}-\mathrm{PCR}$ reactions were performed with the TB Green Premix Ex Taq II (TaKaRa, China) and carried on the ABI QuantStudio ${ }^{\circ} 3$ Real-Time System (Applied Biosystems, USA). The PCR conditions were an initial denaturation at $95^{\circ} \mathrm{C}$ for 10 min, 40 cycles of $95^{\circ} \mathrm{C}$ for $15 \mathrm{~s}$, and $60^{\circ} \mathrm{C}$ for $1 \mathrm{~min}$. The $18 \mathrm{~S}$ rRNA using in Juglans regia [54] was selected as an internal reference gene, and all the reactions were repeated three times. The expression levels of eight DRGs were caculated by using the relative $2^{-\triangle \Delta \mathrm{Ct}}$ method [55].

\section{Abbreviations}

Bio14: precipitations of the driest month; Bio17: precipitations of the driest quarter; DAGs: drought adaptive genes; DEGs: differentially expressed genes; DRGs: drought responsive genes; EAGs: environment adaptive genes; ERGs: environment responsive genes; FC: fold-change; GO: Gene Ontology; KEGG: Kyoto Encyclopedia of Gene and Genome; MDA: malondialdehyde; PC1: principal component 1; Pro: proline; ROS: reactive oxygen species; SS: soluble sugar 


\section{Supplementary Information}

The online version contains supplementary material available at https://doi. org/10.1186/s12864-021-07470-z.

Additional file 1. The supporting data for this manuscript. Table S1. Summary of sequence data from nine samples. Table S2. The GO and KEGG enrichment for up- and down- regulated DEGs at the early stage (3 h) with FC $\geq 2$. Table S3. The GO and KEGG enrichment for up- and down- regulated DEGs at the late stage (12 h) with $F C \geq 2$. Table S4. The primers of qRT-PCR and gene function for 8 selected genes. (XLS $44 \mathrm{~kb}$ )

\section{Acknowledgments}

We are grateful to Zhi-Hao Qian for the help of cultivation and management of seedlings of $P$. stenoptera.

\section{Authors' contributions}

$Y L$ conceived the research project, wrote the paper and analyzed the data, YTS, YXH and JXL revised the paper. All authors are agreed with the content of the manuscript. All authors read and approved the final manuscript.

\section{Funding}

The funders had no role in the experiment design, data analysis, decision to publish or preparation of the manuscript. The authors acknowledge the funding from the National Natural Science Foundation of China (31770225), Henan Science and Technology Project (202102110077), and Henan Agricultural University Science \& Technology Innovation Fund (KJCX2016A2).

\section{Availability of data and materials}

The datasets generated and analysed during the current study are available in the National Center for Biotechnology Information repository, SRX7187821-7187829, BioProject PRJNA589251. The draft genome of $P$. stenoptera are available in https://www.ncbi.nlm.nih.gov/assembly/GCA_ 003123785.1/.

\section{Declarations}

Ethics approval and consent to participate

No specific permits were required for $P$. stenoptera, all samples were collected by researchers following current Chinese regulations.

\section{Consent for publication}

Not applicable.

\section{Competing interests}

The authors declare that have no competing interests.

\section{Author details}

${ }^{1}$ Innovation Platform of Molecular Biology, College of Landcape and Art, Henan Agricultural University, Zhengzhou, China. ${ }^{2}$ School of Life Sciences, Henan University, Kaifeng, China.

Received: 9 February 2020 Accepted: 23 February 2021

Published online: 04 March 2021

\section{References}

1. $\mathrm{Xu} \mathrm{BQ}$, Gao XL, Gao JF, Li J, Yang P, Feng BL. Transcriptome profiling using RNA-seq to provide insights into foxtail millet seedling tolerance to shortterm water deficit stress induced by PEG-6000. J Integr Agr. 2019;18(11): 2457-71.

2. Zhou R, Yu X, Zhao T, Ottosen CO, Rosenqvist E, Wu Z. Physiological analysis and transcriptome sequencing reveal the effects of combined cold and drought on tomato leaf. BMC Plant Biol. 2019;19:377.

3. Cai YF, Wang JH, Zhang L, Song J, Peng LC, Zhang SB. Physiological and transcriptomic analysis highlight key metabolic pathways in relation to drought tolerance in Rhododendron delavayi. Physiol Mol Biol Plants. 2019; 25(4):991-1008.

4. Zhang S, Feng M, Chen W, Zhou X, Lu J, Wang Y, et al. In rose, tranion factor PTM balances growth and drought survival via PIP2;1 aquaporin. Nat Plants. 2019;5(3):290-9.
5. Dong H, Bai L, Zhang Y, Zhang G, Mao Y, Min L, et al. Modulation of guard cell turgor and drought tolerance by a peroxisomal acetate-malate shunt. Mol Plant. 2018;11(10):1278-91.

6. Chen N, Feng J, Song B, Tang S, He J, Zhou Y, et al. De novo transcriptome sequencing and identification of genes related to salt and PEG stress in Tetraena mongolica maxim. Trees. 2019;33:1639-56.

7. You J, Zhang YJ, Liu AL, Li DH, Wang X, Dossa K, et al. Transcriptomic and metabolomic profiling of drought-tolerant and susceptible sesame genotypes in response to drought stress. BMC Plant Biol. 2019;19:267.

8. Yadav BS, Singh S, Srivastava S, Singh NK, Mani A. Whole transcriptome expression profiling and biological network analysis of chickpea during heavy metal stress. J Plant Biochem Biotech. 2019;28(3):345-52.

9. Imadi SR, Kazi AG, Ahanger MA, Gucel S, Ahmad P. Plant transcriptomics and responses to environmental stress: an overview. J Genet. 2015:94(3): 525-37.

10. Simpson GG. Tempo and mode in evolution. New York: Columbia University Press; 1944.

11. Arnold SJ, Pfrender ME, Jones AG. The adaptive landscape as a conceptual bridge between micro- and macroevolution. Genetica. 2001;112(1):9-32.

12. Rellstab C, Gugerli F, Eckert AJ, Hancock AM, Holderegger R. A practical guide to environmental association analysis in landscape genomics. Mol Ecol. 2015;24(17):4348-70.

13. Li Y, Zhang XX, Mao RL, Yang J, Miao CY, Li Z, et al. Ten years of landscape genomics: challenges and opportunities. Front Plant Sci. 2017;8:2136.

14. Arciero E, Kraaijenbrink T, Haber M, Mezzavilla M, Ayub Q, et al. Demographic history and genetic adaptation in the Himalayan region inferred from genome-wide SNP genotypes of 49 populations. Mol Biol Evol. 2018;35(8):1916-33.

15. Brennan RS, Healy TM, Bryant HJ, La MV, Schulte PM, Whitehead A. Integrative population and physiological genomics reveals mechanisms of adaptation in killifish. Mol Biol Evol. 2018;35(11):2639-53.

16. Chen C, Wang H, Liu Z, Chen X, Tang J, Meng F, et al. Population genomics provide insights into the evolution and adaptation of the eastern honey bee (Apis cerana). Mol Biol Evol. 2018;35(9):2260-71.

17. Zhang C, Jiang WB, Wei JX, Han J. Landscape characteristics and its application of Pterocarya stenoptera C. DC. Hunan Agr Sci. 2015;11:147-50.

18. $\mathrm{Xu} L \mathrm{LP}, \mathrm{Pan} \mathrm{YL}, \mathrm{Yu}$ FY. Effects of water-stress on growth and physiological changes in Pterocarya stenoptera seedlings. Sci Hortic. 2015;190:11-23.

19. Yang Y, Li C. Photosynthesis and growth adaptation of Pterocarya stenoptera and Pinus elliottii seedlings to submergence and drought. Photosynthetica. 2016;54(1):120-9.

20. Li LF, Cushman SA, He YX, Ma XF, Ge XJ, Li Y. Landscape genomics reveals genetic evidence of the local adaptation in a widespread woody species, the Chinese wingnut (Pterocarya stenoptera C. DC). 2020; doi:https://doi. org/10.1111/jse.12699

21. Wang PT, Liu H, Hua HJ, Wang L, Song CP. A vacuole localized $\beta$ glucosidase contributes to drought tolerance in Arabidopsis. Chin Sci Bull. 2011;56(33):3538-46.

22. Wang D, Yang C, Dong L, Zhu J, Wang J, Zhang S. Comparative transcriptome analyses of drought-resistant and -susceptible Brassica napus L. and development of EST-SSR markers by RNA-Seq. J Plant Biol. 2015;58(4):259-69.

23. Qi J, Song CP, Wang B, Zhou J, Kangasjärvi J, Zhu JK, et al. Reactive oxygen species signaling and stomatal movement in plant responses to drought stress and pathogen attack. J Integr Plant Biol. 2018;60(9):805-26.

24. Wang $P$, Yang C, Chen $\mathrm{H}$, Song C, Zhang X, Wang D. Transcriptomic basis for drought-resistance in Brassica napus L. Sci Rep. 2017;7:40532.

25. Gao Z, Liu H, Wang H, Li N, Wang D, Song Y, et al. Generation of the genetic mutant population for the screening and characterization of the mutants in response to drought in maize. Chin Sci Bull. 2014;59:766-75.

26. Marcolino-Gomes J, Rodrigues FA, Fuganti-Pagliarini R, Bendix C, Nakayama TJ, Celaya B, Molinari HBC, de Oliveira MCN, Harmon FG, Nepomuceno A. Diurnal oscillations of soybean circadian clock and drought responsive genes. PLoS One. 2014;9:e86402.

27. Kang Z, Babar MA, Khan N, Guo J, Khan J, Islam S, Shrestha S, Shahi D. Comparative metabolomic profiling in the roots and leaves in contrasting genotypes reveals complex mechanisms involved in post-anthesis drought tolerance in wheat. PLoS One. 2019;14:e0213502.

28. Szczepaniec A, Finke D. Plant-vector-pathogen interactions in the context of drought stress. Front Ecol Evol. 2019;7:262.

29. Haider MS, Kurjogi MM, Khalil-Ur-Rehman M, Fiaz M, Pervaiz T, Jiu S, Haifeng J, Chen W, Fang J. Grapevine immune signaling network in response to 
drought stress as revealed by transcriptomic analysis. Plant Physiol Biochem. 2017:121:187-95.

30. Khodakovskaya M, Sword C, Wu Q, Perera IY, Boss WF, Brown CS, et al. Increasing inositol (1,4,5)-trisphosphate metabolism affects drought tolerance, carbohydrate metabolism and phosphate-sensitive biomass increases in tomato. Plant Biotechnol J. 2010;8(2):170-83.

31. Chaves MM, Flexas J, Pinheiro C. Photosynthesis under drought and salt stress: regulation mechanisms from whole plant to cell. Ann Bot. 2009; 103(4):551-60.

32. Colebrook EH, Thomas SG, Phillips AL, Hedden P. The role of gibberellin signalling in plant responses to abiotic stress. J Exp Biol. 2014;217(1):67-75.

33. Huang $B L, L i X$, Liu P, Ma L, Wu W, Zhang $X$, et al. Transcriptomic analysis of Eruca vesicaria subs sativa lines with contrasting tolerance to polyethylene glycol-simulated drought stress. BMC Plant Biol. 2019;19:419.

34. Khan N, Bano A, Rahman MA, Rathinasabapathi B, Babar MA. UPLC-HRMSbased untargeted metabolic profiling reveals changes in chickpea (Cicer arietinum) metabolome following long-term drought stress. Plant Cell Environ. 2018;42(1):115-32.

35. Guerriero G, Legay S, Hausman JF. Alfalfa cellulose synthase gene expression under abiotic stress: a hitchhiker's guide to RT-qPCR normalization. PLoS One. 2014;9(8):e103808.

36. Yang WJ, Du YT, Zhou YB, Chen J, Xu ZS, Ma YZ, et al. Overexpression of TaCOMT improves melatonin production and enhances drought tolerance in transgenic Arabidopsis. Int J Mol Sci. 2019;20(3):652.

37. Xiong L, Ishitani M, Lee H, Zhu JK. The Arabidopsis LOS5/ABA3 locus encodes a molybdenum cofactor sulfurase and modulates cold stress- and osmotic stress-responsive gene expression. Plant Cell. 2001;13(9):2063-84.

38. Mishra M, Das R, Pandey GK. Role of ethylene responsive factors (Erfs) in abiotic stress mediated signaling in plants. E-J Biol Sci. 2009;1 (1):133-46.

39. Qian C, Yan X, Yin H, Fan X, Yin X, Sun P, et al. Transcriptomes divergence of Ricotia lunaria between the two micro-climatic divergent slopes at "evolution canyon" I. Israel Front Genet. 2019:9:506.

40. Nejadsadeghi L, Maali-Amiri R, Zeinali H, Ramezanpour S, Sadeghzade B. Membrane fatty acid compositions and cold-induced responses in tetraploid and hexaploid wheats. Mol Biol Rep. 2015;42(2):363-72.

41. Heath RL, Packer L. Photoperoxidation in isolated chloroplast: I. kinetics and stoichiometry of fatty acids peroxidation. Arch Biochem Biophys. 1968; 125(1):189-98

42. Wang JH, Zhang XM, Chen A, Zhou YW, Chen P, Jiang YF. Response of physiological characteristics and anatomical structure of roots in Amorpha fruticosa seedlings exposed to simulated drought with PEG-6000. Acta Ecol Sin. 2018;38(2):511-7.

43. Rosa M, Hilal M, Gonzalez JA, Prado FE. Low-temperature effect on enzyme activities involved in sucrose-starch partitioning in salt-sressed and saltacclimated cotyledons of quinoa (Chenopodium quinoa Willd.) seedlings. Plant Physiol Biochem. 2009:47(4):300-7.

44. Bates LS, Waldren RP, Teare ID. Rapid determination of free proline for water-stress studies. Plant Soil. 1973;39(1):205-7.

45. Stevens KA, Woeste K, Chakraborty S, Crepeau MW, Leslie CA, MartínezGarcía PJ, et al. Genomic variation among and within six Juglans species. G3-Genes Genom Genet. 2018:8(7):2153-65.

46. Kim D, Langmead B, Salzberg SL. HISAT: a fast spliced aligner with low memory requirements. Nat Methods. 2015;12(4):357-60.

47. Pertea M, Pertea GM, Antonescu CM, Chang TC, Mendell JT, Salzberg SL. StringTie enables improved reconstruction of a transcriptome from RNA-seq reads. Nat Biotechnol. 2015;33(3):290-5.

48. Love Ml, Huber W, Anders S. Moderated estimation of fold change and dispersion for RNA-seq data with DESeq2. Genome Biol. 2014;15(12):550

49. Kanehisaa M, Goto S. KEGG: Kyoto encyclopedia of genes and genomes. Nucleic Acids Res. 2000;28(1):27-30.

50. Dimmer EC, Huntley RP, Alam-Faruque Y, Sawford T, O'Donovan C, Martin MJ, et al. The UniProt-GO annotation database in 2011. Nucleic Acids Res. 2012;40(Database issue):D565-70.

51. Alexa A, Rahnenfuhrer J. topGO: enrichment analysis for gene ontology $R$ Package Version 2.34.0. Available at: https://rdrr.io/bioc/topGO/, 2010.

52. Mao X, Cai T, Olyarchuk JG, Wei L. Automated genome annotation and pathway identification using the KEGG Orthology (KO) as a controlled vocabulary. Bioinformatics. 2005;21:3787-93.

53. Frichot E, Schoville SD, Bouchard G, Francois O. Testing for associations between loci and environmental gradients using latent factor mixed models. Mol Biol Evol. 2013;30(7):1687-99.
54. Gao X, Li Y, Jia C, Li D, Yang Y, Yang G. Identification and expression analysis of the stress resistance gene JrGSTU23 from Juglans regia. J. Zhejiang A\&F Univer. 2018; 35(4):589-595.

55. Livak KJ, Schmittgen TD. Analysis of relative gene expression data using real-time quantitative PCR and the $2^{-\Delta \Delta C T}$ method. Methods. 2001;25(4): $402-8$.

\section{Publisher's Note}

Springer Nature remains neutral with regard to jurisdictional claims in published maps and institutional affiliations.
Ready to submit your research? Choose BMC and benefit from:

- fast, convenient online submission

- thorough peer review by experienced researchers in your field

- rapid publication on acceptance

- support for research data, including large and complex data types

- gold Open Access which fosters wider collaboration and increased citations

- maximum visibility for your research: over $100 \mathrm{M}$ website views per year

At BMC, research is always in progress.

Learn more biomedcentral.com/submissions 